\title{
The effect of thirst on locomotor light escape in rats
}

\author{
DANIEL D. MORIARTY, JR. and ELLETTE K. ELWIN \\ University of San Diego, San Diego, California \\ and \\ JOHN L. ALLEN \\ Point Loma College, San Diego, California
}

(Lawrence Dachowski, Sponsor)

\begin{abstract}
Female rats trained to traverse a runway to escape bright light while thirsty ran faster than ones trained while water-satiated. Taken together with the results of a number of other studies, this observation supports the generalization that hunger or thirst depresses performance on manipulandum escape or avoidance and facilitates performance when locomotion is required for escape or avoidance. We suggest that species-specific defensive reactions elicited by the aversive stimulus interact with the required escape or avoidance response and with food-or water-seeking behavior elicited by deprivation to determine the effect of deprivation on escape or avoidance.
\end{abstract}

Hull's (1943) ideas about irrelevant drive and drive summation provided the impetus for studying the effects of combining different sources of motivation. After reviewing the often contradictory results of such studies, Bolles (1967) concluded, somewhat in jest, that irrelevant drives inhibit responding unless they happen to facilitate it. Interest in this area of research has subsequently declined. Yet the notion of combined sources of motivation continues to be used in the explanation of phenomena as diverse as social facilitation (Zajonc, 1965), aggression (Berkowitz, 1974), interpersonal attraction (Dutton \& Aaron, 1974), and partial reinforcement effects (Amsel, 1958).

In reviewing the effect of hunger or thirst on aversively motivated behaviors, Moriarty, Dachowski, and Patterson (1978) found several studies showing that hunger and thirst depress performance on manipulandum escape or avoidance tasks (e.g., Dachowski, 1964; Davidson, 1971; Griffin, Medearis, \& Hughes, 1973; Leander, 1973; Meyer, Adams, \& Worthen, 1969) and facilitate performance on locomotor escape or avoidance tasks (e.g., Amsel, 1950; Braun, Wedekind, \& Smudski, 1957; Franchina, 1966; Jerome, Moody, Connor, \& Fernandez, 1957). Moriarty et al. (1978) reported the results of a study in which thirst depressed performance when rats were required to press a bar to escape bright light. Taken together, these studies indicate a general pattern of the facilitation of locomotor escape and avoidance by hunger or thirst, and the depression of manipulandum escape or avoidance by hunger or thirst. What is lacking in this literature is the demonstration that a given combination

This research was supported in part by a grant from the University of San Diego Associated Students to the second author. Requests for reprints should be sent to Daniel D. Moriarty, Jr., Department of Psychology, University of San Diego, San Diego, CA 92110. of deprivation and aversive stimulation that depresses performance on a manipulandum task also facilitates performance of a locomotor response. The present study was designed to provide that demonstration by examining the effect of thirst, which has been shown to depress manipulandum light escape, on a locomotor light escape task.

\section{METHOD}

\section{Subjects}

The subjects were 28 naive female albino rats purchased from Simonsen Labs, Inc., Gilroy, California, and were approximately $\mathbf{9 0}$ days old at the beginning of the experiment. They were housed individually under a 14-h-light, 10-h-dark cycle. Purina Lab Chow was always available.

\begin{abstract}
Apparatus
A straight alley constructed of 3/4-in. (1.9-cm) particle board was used. Its internal dimensions were $121 \mathrm{~cm}$ long, $10 \mathrm{~cm}$ wide, and $25 \mathrm{~cm}$ deep. A clear plastic guillotine door, placed $20 \mathrm{~cm}$ from one end of the alley, formed the startbox, and another, placed $25 \mathrm{~cm}$ from the opposite end, formed the goalbox. The floor and walls of the startbox and runway were painted glossy white, and those of the goalbox were gray. The entire apparatus was covered by a clear plastic lid, except that the lid of the goalbox was painted gray. Photoelectric relays placed just past the startbox door in the runway and $15 \mathrm{~cm}$ into the goalbox operated a run timer.

A two-tube flourescent light fixture (Sears) was suspended above the alley so that the tubes were $15 \mathrm{~cm}$ from the lid. The fixture covered the entire length of the alley. Two 40-W flourescent tubes in the fixture provided the aversive bright light. The intensity of the light in the startbox and runway was measured with a photometer (Pasco, Model 9152) and found to be $580 \mathrm{~lx}$, whereas that in the goalbox was $8 \mathrm{~lx}$.

An FM radio was used to provide masking sound during the experiment.
\end{abstract}

\section{Procedure}

The rats were placed on the same water-deprivation schedule described by Moriarty et al. (1978). They were allowed to drink for 45 min each day. The rats were randomly divided into two groups. Those in one group (thirsty) were trained before their drinking period each day, 
whereas the others (water-satiated) were trained after drinking. The time before or after drinking when training occurred varied from 15 to $25 \mathrm{~min}$.

Rats were run in squads of 4 , with 2 from each group in each squad. Within-squad running orders were randomized each day. Squads were run so that each member received Trial 1 before any received Trial 2 , and so on. Each rat was given four trials per day for 5 consecutive days.

A trial began by placing the rat in the startbox facing the door. After $15 \mathrm{sec}$, the startbox door was opened and the rat was allowed to traverse the runway and enter the goalbox.

\section{RESULTS}

Data from the last 2 days of training were subjected to a repeated measures ANOVA in which thirst condition (thirsty or water-satiated) was a between-subjects variable, and days (4 and 5) and trials within days (1-4) were within-subjects variables.

Thirsty rats ran faster than satiated ones. The mean run time for thirsty rats was $2.5 \mathrm{sec}$, whereas that for watersatiated ones was $6.1 \mathrm{sec}$. This difference was significant $[F(1,26)=5.81, p<.025]$. Run time increased over trials. The mean run times for Trials 1 through 4 were $1.8,2.9,5.3$, and $7.2 \mathrm{sec}$, respectively. This effect of trials within days was significant $[F(3,182)=9.15, p<$ .01]. A significant groups $\times$ trials interaction was also observed $[F(3,182)=5.03, p<.01]$. The mean run times of thirsty rats on Trials 1 through 4 were $1.8,2.8$, 2.5 , and $3.3 \mathrm{sec}$, and those for the water-satiated rats were $2.1,3.1,8.2$, and $11.1 \mathrm{sec}$. The tendency to slow down over trials was greater in the water-satiated rats than in the thirsty ones, and the effect of trials was largely due to the behavior of the satiated animals. Neither the main effect of days nor any other interaction was significant.

\section{DISCUSSION}

The results show that thirst facilitated performance on the locomotor light escape task. This is in marked contrast to the results reported by Moriarty et al. (1978), where the same thirst manipulation depressed performance when barpressing was required for light escape. The decrease in performance over trials within days could be interpreted as reflecting a decrease in the motivation to escape the light. Some habituation to the light is a possible mechanism. The significant groups $\times$ trials interaction indicates that the decrease in performance over trials was greater in the water-satiated rats. If habituation did occur, then it did so to a greater extent in water-satiated rats, which is consistent with the observation that habituation is influenced by arousal level (Lader \& Wing, 1964).

The generalization that hunger or thirst depresses manipulandum escape or avoidance but facilitates locomotor escape or avoidance is supported by these results. Taken together with the results of studies previously cited, the effect seems to hold over different training procedures, aversive stimuli, deprivation conditions, and sex of subjects. A possible explanation of this pattern can be derived from Bolles's (1970) suggestion that some escape or avoidance responses are more easily acquired than others because of their compatibility with species-specific defense reactions (SSDRs) elicited by the aversive stimulus, which is an example of the more general concept of preparedness (Seligman, 1970). It seems reasonable to suppose that the SSDR of rats to bright light involve locomotion to an area of lower illumination. If this is correct, then rats ought to be more prepared to learn a locomotor response to escape bright light than to learn a manipulandum escape response that requires stationary behavior. The low barpress rates reported by Moriarty et al. (1978) and the short run times observed in the present study are compatible with this view. It may also be assumed that the deprivation condition, hunger or thirst, elicits locomotor food- or waterseeking behaviors, which may or may not be compatible with the SSDRs and the response required for escape or avoidance. It is suggested that the SSDRs to bright light and water-seeking behaviors elicited by thirst are incompatible with the stationary behavior required for barpressing to escape bright light. In contrast, both are compatible with locomotor escape. The groups $\times$ trials interaction observed in the present study may reflect habituation to the aversive stimulus in both groups and the persistence of water-seeking behaviors in the thirsty group.

Thus, to understand the results of these sorts of studies, it may be necessary to consider the relationship between the SSDRs elicited by the aversive stimulus and the response required for escape or avoidance, as well as the relationship between the required response and the behaviors elicited by the deprivation conditions. If these suggestions are correct, then studies of the effects of combined sources of motivation in different learning situations and species might lend themselves well to the investigation of biological constraints as outlined by Domjan and Galef (1983), who called for a renewed, ecologically relevant, comparative approach.

\section{REFERENCES}

AMSEL, A. (1950). The combination of a primary appetitional need with primary and secondary emotionally derived needs. Journal of Experimental Psychology, 40, 1-14.

AMSEL, A. (1958). The role of frustrative nonreward in noncontinuous reward situations. Psychological Bulletin, 55, 102-119.

BERKOWITZ, L. (1974). Some determinants of impulsive aggression: Role of mediated associations with reinforcements for aggression. Psychological Review, 81, 165-176.

Bolles, R. C. (1967). Theory of motivation. New York: Harper \& Row.

Bolles, R. C. (1970). Species-specific defensive reactions and avoidance learning. Psychological Review, 71, 32-48.

Braun, H. W., Wedekind, C. E., \& SMUdSKI, J. F. (1957). The effect of an irrelevant drive on maze learning in the rat. Journal of $E x-$ perimental Psychology, 54, 148-152.

Dachowski, L. (1964). Irrelevant thirst and light aversion. Psychological Reports, 14, 899-904.

Davidson, R. S. (1971). Effects of food deprivation in free-operant avoidance. Psychological Reports, 29, 1012-1022

Domjan, M., \& GALEF, B. G., JR. (1983). Biological constraints on instrumental and classical conditioning: Retrospect and prospect. Animal Learning \& Behavior, 11, 151-161.

DutTon, D. G., \& AARON, A. P. (1974). Some evidence for heightened sexual attraction under conditions of high anxiety. Journal of Personality \& Social Psychology, 30, 510-517.

Franchina, J. J. (1966). Combined sources of motivation and escape responding. Psychonomic Science, 6, 221-222.

Griffin, P., Medearis, H. D., \& Hughes, W. R. (1973). Food deprivation and free-operant avoidance in pigeons. Bulletin of the Psychonomic Society, 1, 393-394.

Hull, C. L. (1943). Principles of behavior. New York: AppletonCentury-Crofts.

Jerome, E. A., Moody, J. A., Connor, T. J. \& Fernandez, M. B. (1957). Learning in a multiple-door situation under various drive levels. Journal of Comparative \& Physiological Psychology, 50, 588-591.

LADER, M. H., \& WING, L. (1964). Habituation of the psycho-galvanic reflex in patients with anxiety states and normal subjects. Journal of Neurology, Neurosurgery, \& Psychiatry, 27, 210-218.

LEANDER, J. D. (1973). Effects of food deprivation on free-operant avoidance behavior. Journal of the Experimental Analysis of Behavior, 19, 17-24.

Meyer, M. E., Adams, W. A., \& Worthen, U. K. (1969). Deprivation and escape conditioning with various intensities of shock. Psychonomic Science, 14, 212-214.

Moriarty, D. D., JR., Dachowski, L., \& Patterson, M. Y. (1978). Effect of thirst and changing thirst on bar-pressing to escape bright light. American Journal of Psychology, 91, 691-696.

Seligman, M. E. P. (1970). On the generality of the laws of learning. Psychological Review, 77, 406-418.

ZAJONC, R. B. (1965). Social facilitation. Science, 149, 269-274. 